Check for updates

Cite this: Phys. Chem. Chem. Phys., $2019,21,18278$

Received 24th June 2019 Accepted 30th July 2019

DOI: $10.1039 / c 9 c p 03552 d$

rsc.li/pccp

\title{
What a difference a methyl group makes - probing choline-urea molecular interactions through urea structure modification $\dagger$
}

\author{
Liliana P. Silva, (D) $\ddagger^{a}$ Catarina F. Araújo, (D) $\ddagger^{a}$ Dinis O. Abranches, (D) a \\ Manuel Melle-Franco, (iD a Mónia A. R. Martins, iD abc Mariela M. Nolasco, (D) a \\ Paulo J. A. Ribeiro-Claro, (D) ${ }^{a}$ Simão P. Pinho (iD bc and João A. P. Coutinho (ID) *a
}

\begin{abstract}
There is a lack of fundamental knowledge on deep eutectic solvents, even for the most extensively studied mixtures, such as the mixture of cholinium chloride and urea, which prevents a judicious choice of components to prepare new solvents. The objective of this work is to study and understand the fundamental interactions between cholinium chloride and urea that lead to the experimentally observed melting temperature depression. To do so, the structure of urea was strategically and progressively modified, in order to block certain interaction centres, and the solid-liquid equilibrium data of each new binary system was experimentally measured. Using this approach, it was concluded that the most important interaction between cholinium chloride and urea occurs through hydrogen bonding between the chloride anion and the amine groups. Any blockage of these groups severely hampers the melting point depression effect. Raman spectroscopy and DFT calculations were utilized to study in more detail this hydrogen bonding and its nuances.
\end{abstract}

\section{Introduction}

The so-called deep eutectic solvents (DES) have emerged at the beginning of this century as possible substitutes for hazardous organic solvents. ${ }^{1-5}$ They are usually defined as a mixture of a hydrogen bond acceptor (HBA) and a hydrogen bond donor (HBD) that form strong hydrogen bonds, ${ }^{4}$ leading to melting temperatures substantially lower than those predicted by assuming an ideal liquid mixture ${ }^{6}$ or those presented by the individual pure components. ${ }^{5}$ Cholinium chloride $(\mathrm{ChCl})$ is one of the most recurring substances used to prepare DES and a large set of experimental solid-liquid equilibrium data on mixtures containing $\mathrm{ChCl}$ is already available in the literature, ${ }^{7-11}$ with most of the DES prepared presenting low toxicity and being readily biodegradable. ${ }^{12,13}$

Even though the deep eutectic solvent composed of urea and cholinium chloride was identified as a green solvent in $2003,{ }^{14}$ its structure and molecular interactions, along with macroscopic

\footnotetext{
${ }^{a}$ CICECO - Aveiro Institute of Materials, Department of Chemistry, University of Aveiro, 3810-193 Aveiro, Portugal. E-mail: jcoutinho@ua.pt

${ }^{b}$ Associate Laboratory LSRE-LCM, Department of Chemical and Biological Technology, Polytechnic Institute of Bragança, 5300-253 Bragança, Portugal

${ }^{c}$ Mountain Research Center - CIMO, Polytechnic Institute of Bragança, 5300-253 Bragança, Portugal

$\dagger$ Electronic supplementary information (ESI) available. See DOI: 10.1039/c9cp03552d

₹ Equally contributing authors.
}

phenomena such as solid-liquid equilibria (SLE), still hold some mysteries. A recent study by van den Bruinhorst and co-workers ${ }^{15}$ compares the currently available SLE data for the cholinium chloride/urea system, pointing out that the liquidus temperatures reported by Abbott and co-workers, ${ }^{14}$ who measured freezing temperatures, are consistently lower than the melting temperatures reported by other authors ${ }^{16,17}$ due to the phenomenon of supercooling, while Meng et al. ${ }^{16}$ attribute the observed discrepancies to the presence of water. Even though not shown in the SLE diagrams reported, XRD data ${ }^{17}$ suggest the formation of a 1:2 cholinium chloride-urea cocrystal, whose structure is yet to be explored.

Several experimental and theoretical studies ${ }^{18-38}$ have been devoted to studying the liquid structure and main interactions in the cholinium chloride-urea eutectic, generally pointing to a complex mesh of "overall similar interactions between all constituents" as expressed in Zahn's hypothesis "similia similibus solvuntur" ("like dissolves like"). ${ }^{19}$ Ashworth and co-workers ${ }^{37}$ used DFT calculations to assess intermolecular interactions among the cation, anion and hydrogen bond donor. They argue that urea $\cdots$ chloride contacts might compete with cholinium $\cdots$ urea interactions since individual $\mathrm{OH} \cdots \mathrm{O}=\mathrm{C}$ hydrogen bonds rank as stronger than $\mathrm{N}-\mathrm{H} \cdots \mathrm{Cl}$ contacts, which show up as mediumstrength interactions, surpassed by $\mathrm{OH} \cdots \mathrm{Cl}$ and $\mathrm{N}-\mathrm{H} \cdots \mathrm{O}=\mathrm{C}$ bonds. This view is only partially supported by the neutron diffraction study of Hammond and colleagues, ${ }^{31}$ performed at $303 \mathrm{~K}$, describing a "radially layered sandwich structure" where 
the cholinium cation's - $\mathrm{OH}$ and urea's $-\mathrm{NH}$ moieties strongly interact with the chloride anion while maintaining softer cholinium...urea and urea..urea contacts. Using the same technique, Gilmore and co-workers ${ }^{32}$ showed that at $338 \mathrm{~K}$ the $\mathrm{OH} \cdots \mathrm{Cl}$ correlation is weakened in favour of forming $\mathrm{OH} \cdots \mathrm{OH}$ contacts, while the urea...Cl interaction remains dominant. Charge transfer between the chloride anion and the hydrogen bond donor was initially proposed by Carriazo et $a l^{39}$ as constituting the main driver for the melting point depression, yet his view has since been disputed by Zahn and co-workers' $a b$ initio molecular dynamics simulation, ${ }^{20}$ suggesting that charge transfer occurs mainly between the cation and the anion. Another $a b$ initio study, performed by Wagle and colleagues, ${ }^{23}$ proposes that the melting points of three cholinium chloride based DES correlate with the bond order of the cholinium ...chloride interaction but not with the bond order of the HBD $\cdots$ chloride contacts. Migliorati and colleagues ${ }^{29}$ compared eutectic mixtures based on urea and either cholinium chloride or butyltrimethylammonium chloride, finding that while the urea...chloride interaction is relatively favoured in the latter this does not translate into a more pronounced melting point depression. It is then clear that the contribution of the HBD *anion interaction to the melting point depression remains controversial. Our own past vibrational spectroscopy study of the cholinium chloride/urea system ${ }^{38}$ failed to unambiguously isolate the vibrational fingerprint of the urea $\cdots$ chloride interaction so that

Table 1 Source, purity and melting properties of the substances used in this work

\begin{tabular}{lllll}
\hline Compound & Supplier & Purity $\%$ & $T_{\mathrm{m}} / \mathrm{K}$ & $\Delta_{\mathrm{m}} h / \mathrm{kJ} \mathrm{mol}^{-1}$ \\
\hline Cholinium chloride & Acros organics & 98 & $597^{10}$ & $4.3^{10}$ \\
Urea & Analar & 99.5 & $408.2^{a}$ & $14.6^{40}$ \\
Methylurea & Acros organics & 97 & $372.2^{a}$ & $12.5^{41}$ \\
1,1-Dimethylurea & Acros organics & 98 & $452.5^{a}$ & $29.11^{42}$ \\
1,3-Dimethylurea & Acros organics & 98 & $379.8^{a}$ & $13.62^{43}$ \\
Thiourea & Acros organics & 99 & $454.9^{a}$ & $12.55^{44}$
\end{tabular}

${ }^{a}$ Measured in this work. its importance to the melting point depression could not be fully ascertained.

Better knowledge of the molecular interactions of cholinium chloride in deep eutectic solvents would lead to a wiser and more rigorous choice of components to prepare new DES and, thus, is of paramount importance. The main objective of the present work is to understand the fundamental interactions between cholinium chloride and urea by strategically modifying the structure of urea to block specific interaction sites. For that purpose, the solid-liquid equilibrium phase diagrams of five binary mixtures composed of cholinium chloride and urea, thiourea, methylurea, 1,3-dimethylurea or 1,1-dimethylurea were measured and analysed. Raman spectroscopy was used as an auxiliary tool to corroborate our findings. The objective of using thiourea is to probe the importance of the carbonyl group in the cholinium-urea interaction, whilst the methylurea series is used to assess the role of urea's amine groups in said interaction.

\section{Experimental details}

\section{Chemicals}

Pertinent properties for the substances experimentally used in this work are reported in Table 1 . Their chemical structures are depicted in Fig. 1. Due to its high hygroscopicity, cholinium chloride was dried under vacuum (0.1 Pa and $298 \mathrm{~K}$ ) for at least $72 \mathrm{~h}$ before use. The remaining compounds were stored at room temperature and used as received. The water content of each compound was measured using a Metrohm 831 KarlFischer coulometer with the analyte Hydranal ${ }^{\circledR}$-Coulomat AG from Riedel-de Haën and found to be lower than 600 ppm for cholinium chloride and lower than $10 \mathrm{ppm}$ for the remaining substances.

\section{Solid-liquid equilibrium phase diagrams}

All samples were prepared inside a dry argon glovebox chamber, weighing each amount of individual pure component inside a
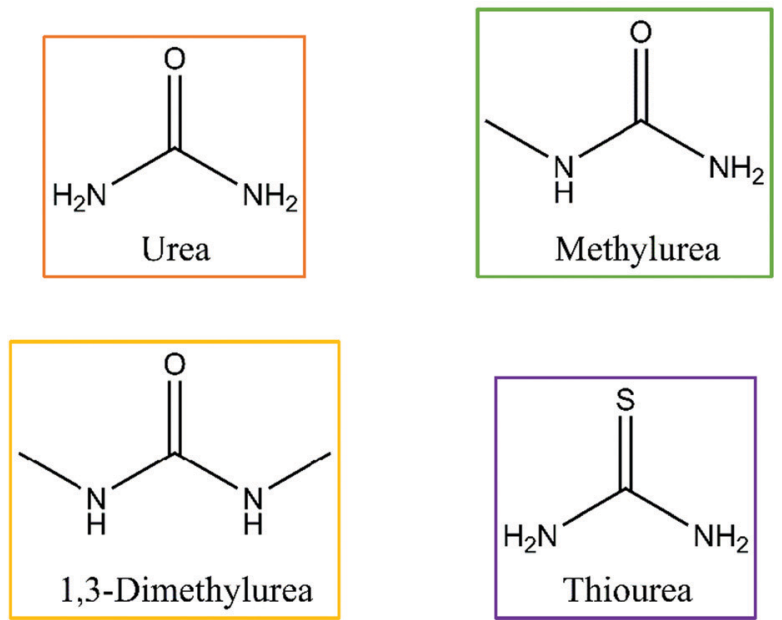

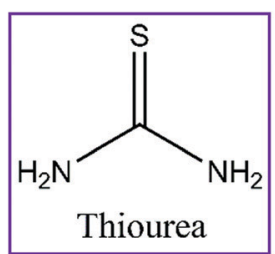

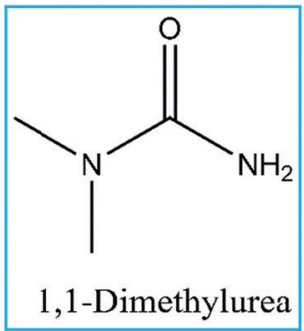

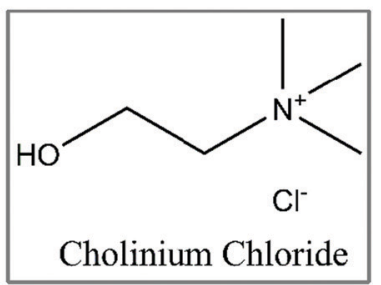

Fig. 1 Chemical structures of the chemical compounds used in this work. 
vial using an analytical balance (ALS 220-4N from Kern) with an accuracy of $\pm 0.002 \mathrm{~g}$. For each system its entire composition range was covered. The vials were then heated under stirring, until complete fusion, and then recrystallized. After this heat cycle treatment, the mixtures obtained presented (i) a paste like consistency or (ii) completely solid recrystallization. Depending on the physical state of the final mixture, different melting temperature measurement methods were applied. In case (i), a visual method using an oil bath was applied, where the mixtures were inserted in an oil bath and gradually heated until complete melting. The temperature was controlled with a PT100 probe that was previously calibrated. For case (ii), the solid mixtures were ground inside the glove box chamber and the powder was filled into a glass capillary. The melting point was determined using a melting point device from Bucchi (Model M 585, a temperature resolution of $0.1 \mathrm{~K}$ ) with a heating rate of $0.1 \mathrm{~K} \mathrm{~min}^{-1}$. Regardless of the method used, all measurements were repeated at least three times, possessing an estimated reproducibility of $\pm 1.4 \mathrm{~K}$ (see the ESI $\dagger$ ).

It has been shown in the literature that some deep eutectic solvents, specifically malonic acid-based systems, ${ }^{45}$ may undergo decomposition during their preparation using the heating cycle described above. However, for all systems studied, no decomposition was detected in any of the mixtures prepared. Moreover, all solid-liquid equilibrium data obtained are consistent, without any indication of component decomposition.

\section{Raman spectroscopy}

Raman spectra were collected using a WITec alpha300 RAS+ (WITec, Ulm, Germany) Raman microscope. An Nd:YAG laser operating at $532 \mathrm{~nm}$ was used as the excitation source with the power set at $25 \mathrm{~mW}$. The samples were enclosed in capped NMR tubes, previously filled inside a dry argon glovebox chamber, and placed within a homemade heating apparatus of the HarneyMiller type. The temperature inside the sample holder was monitored using a thermocouple connected to a multimeter. Raman spectra of the eutectic mixtures based on urea, methylurea and 1,3-dimethylurea, as well as those of their pure components, were collected at $150{ }^{\circ} \mathrm{C}, 110{ }^{\circ} \mathrm{C}$ and $130{ }^{\circ} \mathrm{C}$, respectively, thereby ensuring that each pair of pure HBD and the corresponding eutectic mixture was in the liquid state. Since cholinium chloride does not melt, its spectrum was collected at $100{ }^{\circ} \mathrm{C}$ after equilibrating for 20 minutes to ensure that the polymorphic transition into the beta-cholinium chloride form ${ }^{46,47}$ had been completed.

\section{Computational details}

\section{$A b$ initio calculations}

The structures of urea, thiourea, methylurea, 1,3-dimethylurea and 1,1-dimethylurea, along with their interaction pair with themselves or with the chloride anion, were optimized at the M06-2X level of theory with the 6-311++G(d,p) basis set in the gas phase. In addition, the complete series was also computed with the $6-31+G(d, p)$ basis set optimized in the gas phase and later embedded in the generic ionic liquid solvation model,
SMD-GIL. ${ }^{48}$ Prior to the DFT calculations, the conformational space was systematically explored with molecular dynamics 100 ps runs with a tight binding novel Hamiltonian. ${ }^{49}$ Frequencies were calculated to ensure that all optimized geometries were real minima (no negative eigenvalues). CM5 point charges based on the Hirshfeld partition scheme were computed for all minima. All DFT calculations were performed with the Gaussian 09 Rev A.02 package. ${ }^{50}$ Interaction energies $\left(E_{\text {int }}\right)$ were calculated by subtracting the electronic energy without zero-point correction of the constituents $\left(E_{\mathrm{M} 1}\right.$ and $\left.E_{\mathrm{M} 2}\right)$ from that of the interacting pair $\left(E_{\text {Pair }}\right)$ in the gas phase or embedded in a solvent continuum:

$$
E_{\text {int }}=E_{\text {Pair }}-E_{\mathrm{M} 1}-E_{\mathrm{M} 2} \text {. }
$$

In addition to the point charges, the electrostatic potential mapped onto the electron density was also computed for the urea family. The results obtained are presented in the ESI $\dagger$ as visual aids. They were calculated using TURBOMOLE (software package TmoleX $\left.{ }^{51}\right)$, employing the $6-311++\mathrm{G}(\mathrm{d}, \mathrm{p})$ basis set in the gas phase and the M06-2X level of theory.

\section{Thermodynamic framework}

The solid-liquid equilibrium curve of a component within a eutectic-type mixture, when no solid-phase transitions are present, can be described using the following equation: ${ }^{52}$

$$
\ln \left(x_{i} \cdot \gamma_{i}\right)=\frac{\Delta_{\mathrm{m}} h_{i}}{R} \cdot\left(\frac{1}{T_{\mathrm{m}, i}}-\frac{1}{T}\right)+\frac{\Delta_{\mathrm{m}} C p_{i}}{R} \cdot\left(\frac{T_{\mathrm{m}, i}}{T}-\ln \frac{T_{\mathrm{m}, i}}{T}-1\right)
$$

where $x_{i}$ is the mole fraction of component $i$ in the liquid phase, $\gamma_{i}$ its activity coefficient, $\Delta_{\mathrm{m}} h_{i}$ its melting enthalpy, $T_{\mathrm{m}, i}$ its melting temperature and $\Delta_{\mathrm{m}} C p_{i}$ its heat capacity change upon melting, whilst $R$ is the ideal gas constant and $T$ is the absolute temperature of the system. Since the contribution of the last term present in eqn (2) is typically negligible and the value of $\Delta_{\mathrm{m}} C p_{i}$ is usually not available for the compounds used in this work, eqn (2) is well approximated by: ${ }^{6,53}$

$$
\ln \left(x_{i} \cdot \gamma_{i}\right)=\frac{\Delta_{\mathrm{m}} h_{i}}{R} \cdot\left(\frac{1}{T_{\mathrm{m}, i}}-\frac{1}{T}\right)
$$

Eqn 3 is useful in two ways: it can be used to predict the SLE phase diagram of a mixture considering its liquid phase as ideal by setting $\gamma_{i}=1$, or it can be used to calculate the activity coefficients of the components in a mixture using available experimental SLE data. As such, solid-liquid phase diagrams can be used to assess the liquid phase non-ideality of mixtures and, thus, the specific interactions between their components.

\section{Results and discussion}

The five SLE phase diagrams measured are depicted in Fig. 2 along with the ideal liquid phase curves and the experimental activity coefficients, calculated using eqn (3) and the melting properties in Table 1. Detailed experimental data are reported in Table S1 of the ESI. $\dagger$ Since Abbott et al. ${ }^{14}$ already reported the freezing temperatures for the system cholinium chloride/urea, in a small composition range, and for the remaining systems, 

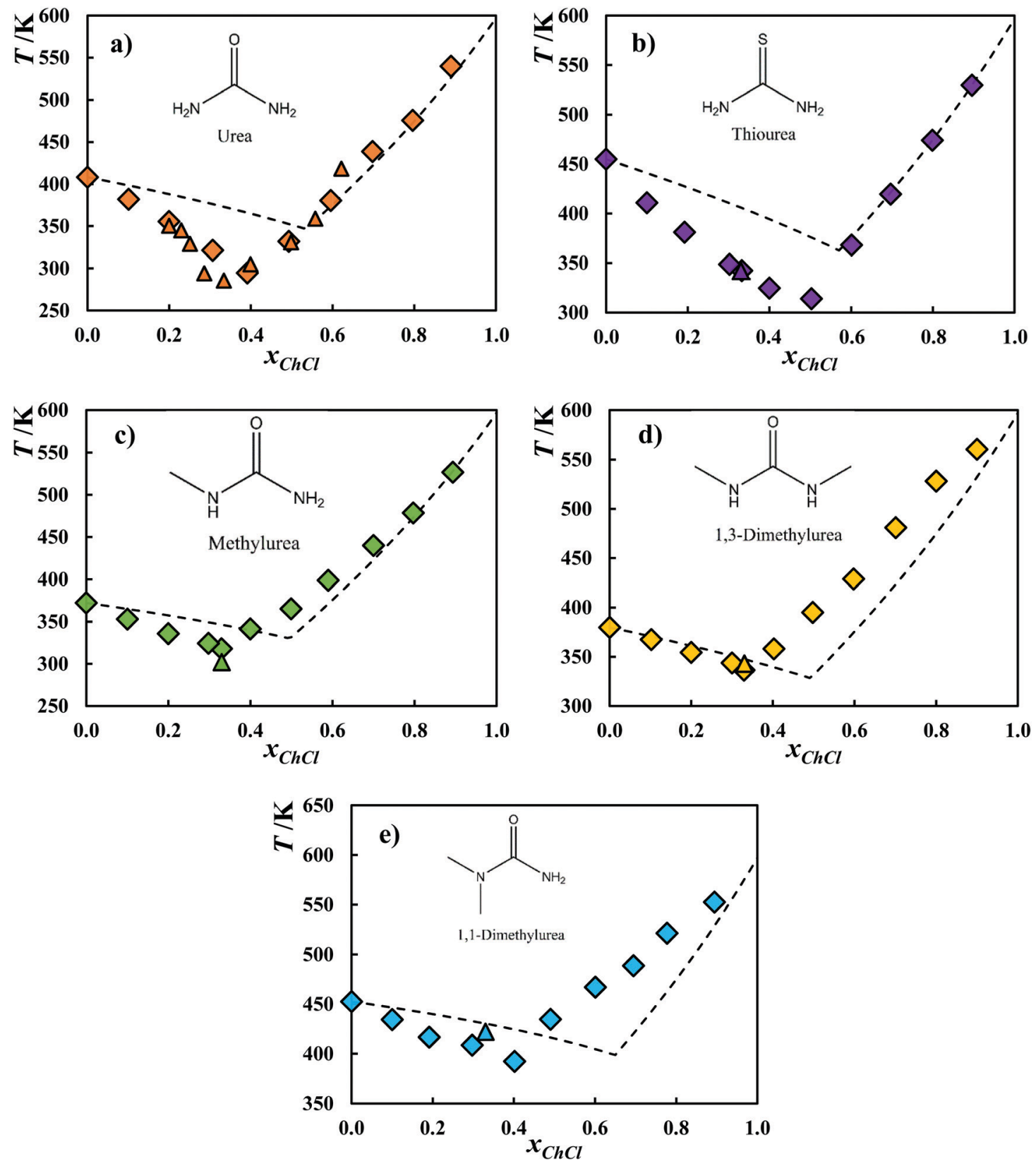

Fig. 2 Solid-liquid equilibrium phase diagrams for the binary mixtures composed of cholinium chloride and (a) urea, (b) thiourea, (c) methylurea, (d) 1,3-dimethylurea or (e) 1,1-dimethylurea, along with the corresponding activity coefficients ( $\bigcirc$ for cholinium chloride and $\square$ for the urea-family component). The symbol $\diamond$ represents the experimental data measured in this work (see Table S1, ESI $\dagger$ ) while the symbol $\triangle$ represents experimental data taken from Abbott and coworkers. ${ }^{14}$ Dashed lines represent the ideal-liquid phase mixture behavior. The structure of each modified urea is include as an inset.

in a 2:1 mole proportion, these data are also included. An extensive comparison with literature data for the system cholinium chloride/urea is shown in Fig. S1 in the ESI. $\dagger$ The main reason for the discrepancies observed is related to the high hygroscopicity of cholinium chloride as shown by Meng et al. ${ }^{16}$ This is the main reason for the careful preparation of all mixtures in a water-free environment as described in the Experimental section.

We first examine the systems cholinium chloride/urea and cholinium chloride/thiourea, the sole difference being the replacement of urea's carbonyl group by thiourea's thionyl group.
The melting curves and activity coefficients (calculated using eqn (3)) of the components in both systems were merged into Fig. 3 to simplify comparison and analysis.

Fig. 3a reveals an almost identical behaviour in the melting curve of cholinium chloride when mixed with urea or thiourea. In turn, this corresponds to a very similar behaviour of its activity coefficients in both systems, as Fig. 3c shows. Both urea and thiourea also present a remarkably similar behaviour when mixed with cholinium chloride. This may not be easy to see in Fig. $3 \mathrm{~b}$ but is clear in Fig. 3d, which depicts similar activity 

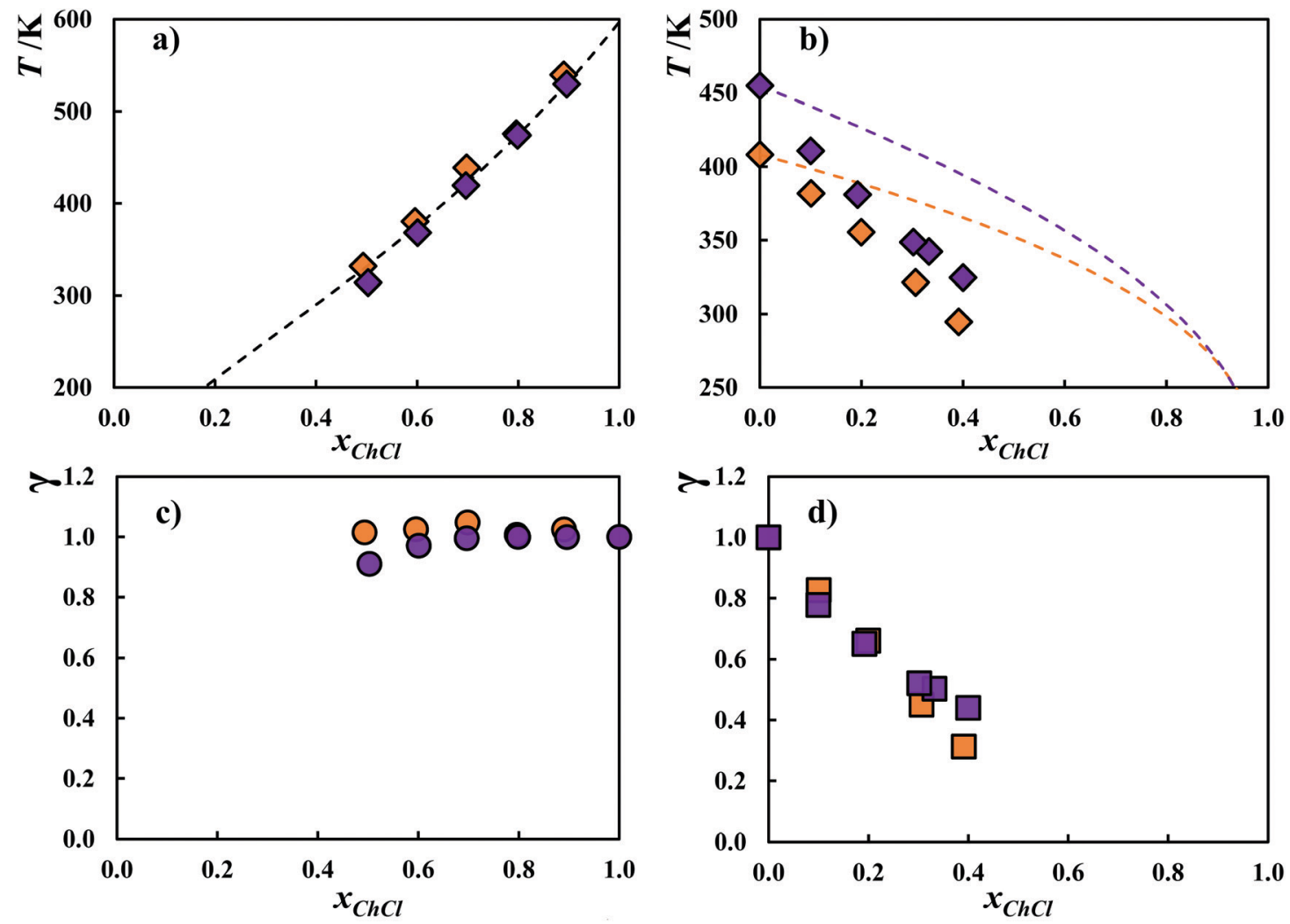

Fig. 3 Experimental melting curve $(\diamond)$ of each component in the binary systems composed of cholinium chloride and urea (orange) or thiourea (purple). The dashed lines represent the ideal melting curve of each component. The corresponding activity coefficients ( $\bigcirc$ for cholinium chloride and $\square$ for the urea family) are also included.

coefficients for both substances. Taking all this into account, it can be safely assumed that the main interactions between cholinium chloride and urea do not involve its carbonyl group, i.e. the interactions between urea and cholinium chloride are not dominated by the carbonyl group interactions in the mixture.

Fig. 4 presents the atomic charges for the urea family, calculated as described in the computational details section (a comparison between the $\mathrm{C} 2$ and $\mathrm{D} 2 \mathrm{~h}$ conformations of urea and thiourea is included in Fig. S2 of the ESI†). The sulphur atom provides thiourea with a larger negative surface than urea, albeit with a more disperse (less intense) charge (see Fig. S3 for a visual aid, ESI $\dagger$ ). On the other hand, the electrostatic field generated by the protons is very similar for both molecules. As such, and considering that the swap of an oxygen for a sulphur does not significantly alter the interactions between urea and cholinium chloride, it can be safely assumed that cholinium chloride's main interactions with urea are via the positive hydrogen atoms in the amine groups, which may form a hydrogen bond with the chloride anion of cholinium chloride.

The interaction energies for the chloride anion with thiourea or urea and for cholinium chloride with two molecules of thiourea or two molecules of urea, embedded in a generic liquid solvent continuum, were computed. Thiourea compounds are stabilized versus urea in excess of 16 and $24 \mathrm{~kJ} \mathrm{~mol}^{-1}$ respectively. This arises from the substantial differences in the charges of the carbonyl and the thionyl groups for both molecules, and/or enhanced dispersion interactions with the larger, thus more polarizable, sulphur atom. The fact that the thermodynamic behaviour of thiourea and urea, when mixed with cholinium chloride, is essentially similar means that neither of these interactions should play a fundamental role in the previously reported deviations from ideality.

After analysing the effect of the exchange of the oxygen of urea for the sulphur of thiourea, which did not seem to induce significant differences in the behaviour of the SLE phase diagrams of these compounds, the next step is to structurally modify the amine groups of urea by methylation. The results are summarized in Fig. 5, which shows cholinium chloride combined with urea, methylurea or 1,3-dimethylurea. In this series the amine groups of urea are progressively blocked by methylation.

Fig. 5a clearly shows a trend in the behaviour of cholinium chloride with the blockage of the amine groups in urea. Initially, cholinium chloride behaves ideally when mixed with urea. However, when mixed with methylurea, cholinium chloride reveals positive deviations from ideality, which are further enhanced in the 1,3-dimethylurea system. A complementary trend is seen in Fig. 5d, where urea shows the largest negative deviations from ideality, while 1,3-dimethylurea has an almost ideal behaviour. This supports the hypothesis, presented from the analysis of the urea and thiourea systems, that the main interactions between cholinium chloride and urea would occur between the chloride and the protons at the amine groups. As they get replaced by 
a)

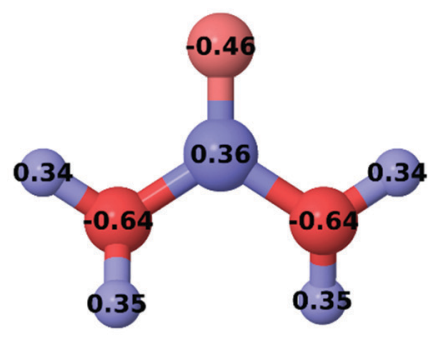

c)

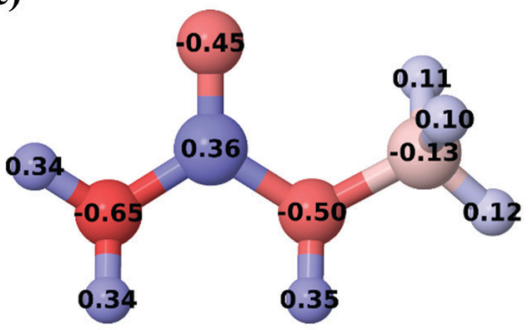

b)

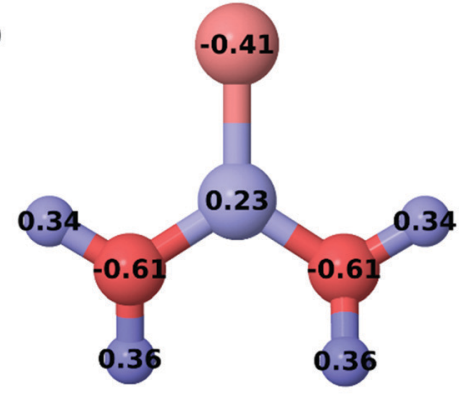

d)

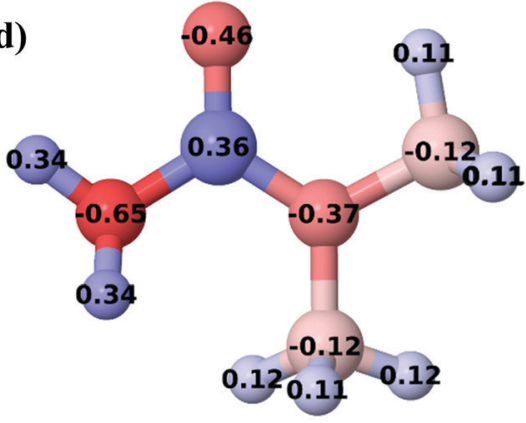

e)

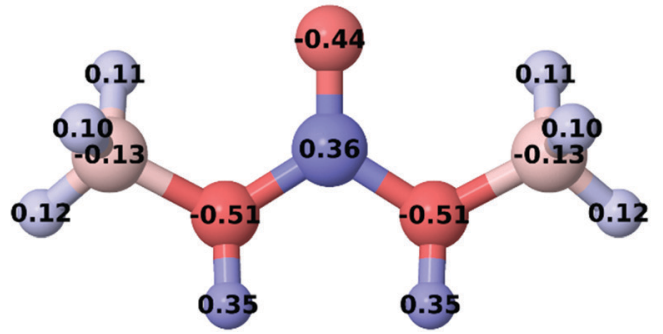

Fig. 4 Partial charges at the M06-2X-GIL-6-31+g(d,p)/M06-2X-6-31+g(d,p) level of theory for (a) urea, (b) thiourea, (c) methylurea, (d) 1,3-dimethylurea and (e) 1,1-dimethylurea. Red represents negative charges and blue represents positive charges while white is neutral.

methyl groups (Fig. S4, ESI $\dagger$ ), cholinium chloride loses any energetic advantage to interact with the urea family and presents positive deviations from ideality. A similar behaviour was observed by us in previous work, where cholinium chloride presented positive deviations from ideality when mixed with salts not able to act as hydrogen bond donors. ${ }^{7}$

Raman spectroscopy provides further confirmation that the chloride anion prefers to interact with urea's $\mathrm{N}-\mathrm{H}$ moieties and that the interaction becomes less favourable as the $\mathrm{N}-\mathrm{H}$ are blocked by methylation. The strength of the $\mathrm{N}-\mathrm{H} \cdots$ chloride interactions can be inferred from the frequency of the $\mathrm{NH}$ stretching modes as depicted in Fig. 6, where the upper panels show the sum Raman spectra of the pure liquid urea-family component and the beta polymorph of cholinium chloride while the lower panels display the spectra of the real eutectic mixtures in the liquid state. The broad spectral profiles above $3100 \mathrm{~cm}^{-1}$ result from a sum of contributions including cholinium's $\mathrm{O}-\mathrm{H}$ stretching mode $^{46}$ and urea's and alkylurea's N-H symmetric and asymmetric stretching modes plus combination/overtone modes. ${ }^{54-56}$ A peak deconvolution procedure was applied to estimate the maxima of the symmetric $\mathrm{N}-\mathrm{H}$ stretching contributions, highlighted in blue. As a general trend, the symmetric $\mathrm{N}-\mathrm{H}$ stretch appears at lower wavenumbers in the spectra of the eutectic mixtures relative to the spectra of the pure components. In the latter, the $\mathrm{N}-\mathrm{H}$ stretch contributions stem only from $\mathrm{N}-\mathrm{H} \cdots \mathrm{O}=\mathrm{C}$ contacts while the spectra of the real eutectic mixtures feature both $\mathrm{N}-\mathrm{H} \cdots \mathrm{O}=\mathrm{C}$ and $\mathrm{N}-\mathrm{H} \cdots \mathrm{Cl}^{-}$interactions (since $\mathrm{N}-\mathrm{H} \cdots \mathrm{O}-\mathrm{H}$ contacts are expected to be negligible ${ }^{31}$ ). Being so, a possible explanation for the decrease in the $\mathrm{N}-\mathrm{H}$ frequency is that upon forming the eutectic mixture a portion of the $\mathrm{N}-\mathrm{H} \cdots \mathrm{O}=\mathrm{C}$ contacts are disrupted by the formation of stronger $\mathrm{N}-\mathrm{H} \cdots \mathrm{Cl}^{-}$contacts.

The difference in frequency between the pure and mixture spectra can then be taken as a measure of the strength of $\mathrm{N}-\mathrm{H} \cdot \mathrm{Cl}^{-}$ contacts in the different eutectic systems, with the urea-based eutectic showing the strongest deviation, while the 1,3-dimethylurea system features the lowest frequency shift. Such a tendency is evident in the plot of the $\mathrm{N}-\mathrm{H}$ stretching frequency shift against the $\mathrm{N}-\mathrm{H} \cdot \mathrm{Cl}^{-}$energy of interaction (estimated by DFT as described in the Experimental section), depicted in Fig. 7. This supports the idea that for eutectic mixtures based on cholinium chloride and urea, methylurea or 1,3-dimethylurea, the melting point depression is mostly ruled by the strength of the $\mathrm{N}-\mathrm{H} \cdots \mathrm{Cl}^{-}$interactions, which become weaker as the degree of methylation increases.

Finally, the system cholinium chloride/1,1-dimethylurea is analysed. Fig. 8 shows a comparison between the systems cholinium chloride + urea, 1,3-dimethylurea or 1,1-dimethylurea. 

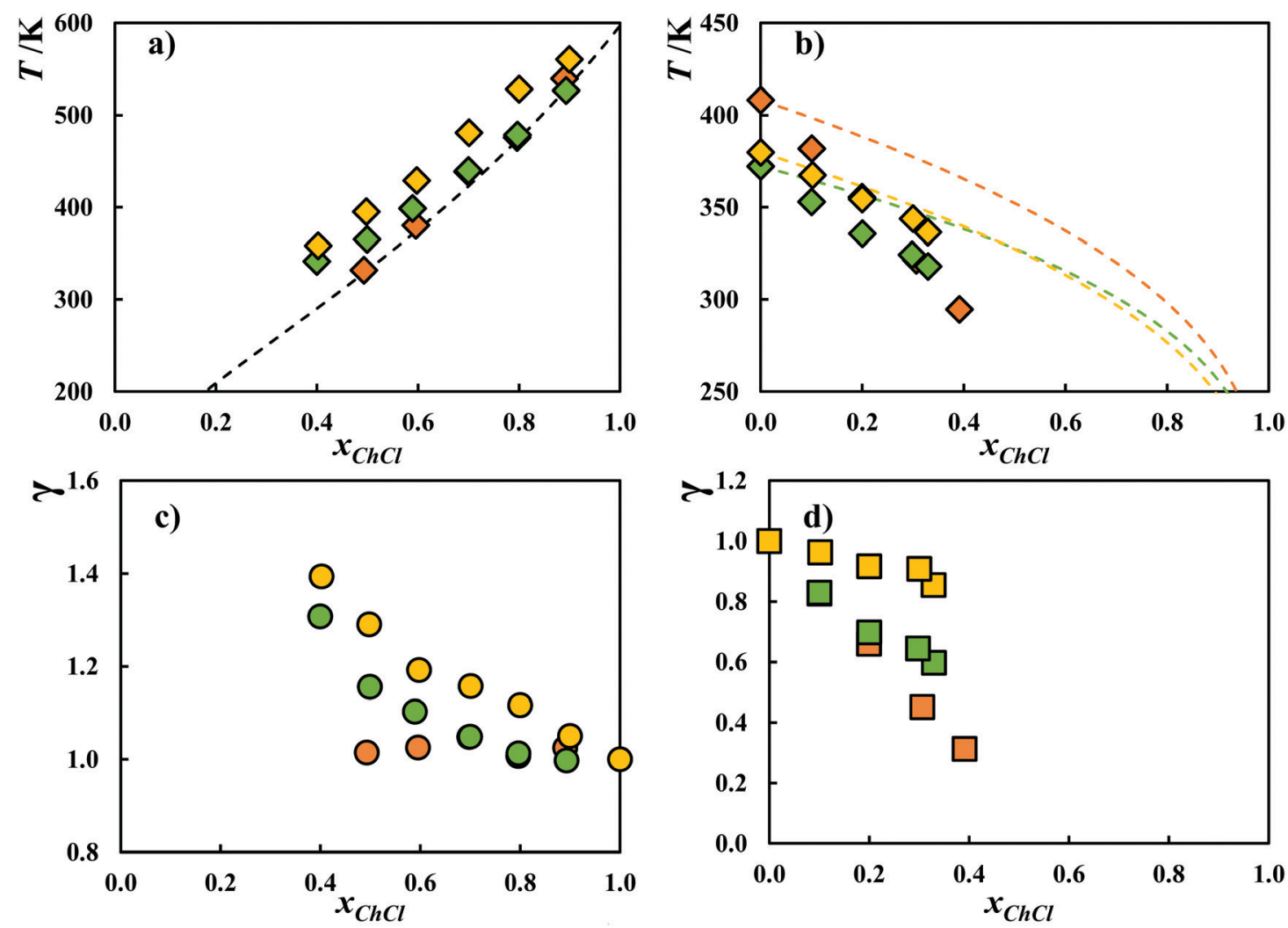

Fig. 5 Experimental melting curve $(\diamond)$ of each component in the binary systems composed of cholinium chloride and urea (orange), methylurea (green) or 1,3-dimethylurea (yellow). The dashed lines represent the ideal melting curve of each component. The corresponding activity coefficients ( $\bigcirc$ for cholinium chloride and $\square$ for the urea-family component) are also included.
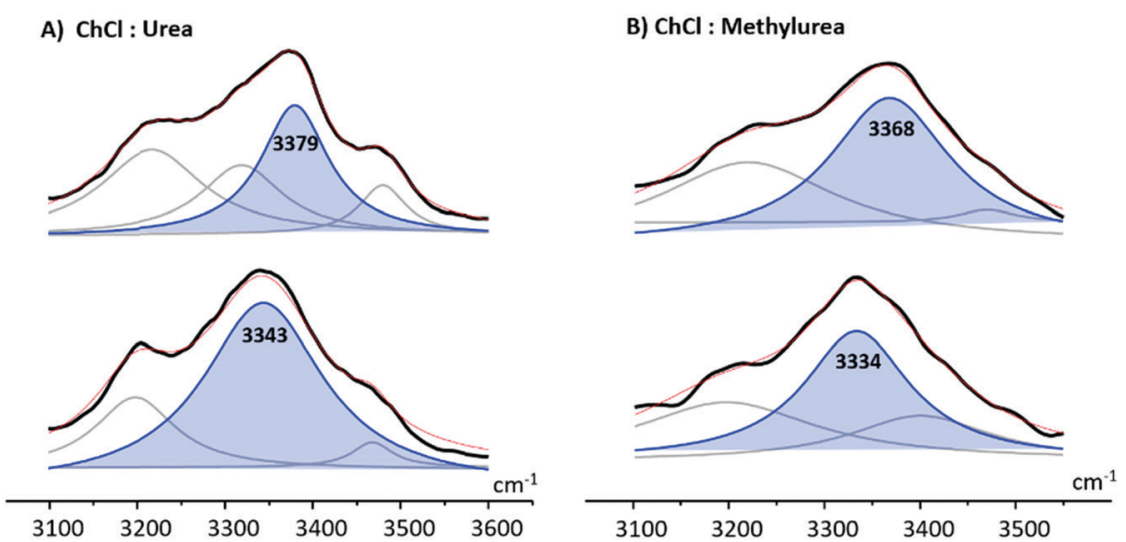

C) $\mathrm{ChCl}:$ 1,3-dimethylurea

Fig. 6 Raman spectra and peak deconvolution of eutectic mixtures based on cholinium chloride and (A) urea, (B) methylurea, and (C) 1,3-dimetylurea; upper panel: sum spectra of the pure liquid HBD and beta-cholinium chloride; lower panel: spectra of the actual eutectic mixture. Black line: experimental spectra; red line: sum of fitted peak contributions.

Cholinium chloride presents positive deviations from ideality when mixed with 1,1-dimethylurea, as expressed by its activity coefficients, which are slightly higher than for the system cholinium chloride/1,3-dimethylurea, as shown in Fig. 8c. This suggests that fully blocking an amine group of urea (1,1-dimethylurea, see Fig. S5 for a visual aid, ESI $\dagger$ ), instead of partially blocking its two amine groups (1,3-dimethylurea), further undermines the ability of cholinium chloride to interact with urea. This can be explained by a preference of the chloride anion to interact with the two bottom protons of the urea molecule, in a similar organisation to the head-to-tail arrangement of urea in its pure form, since these protons establish a continuum positive area between them ${ }^{57}$ as opposed to two positive surfaces separated by a more neutral charged zone.

Contrary to the trend of cholinium chloride, Fig. $8 \mathrm{~d}$ reveals that 1,1-dimethylurea presents negative deviations from ideality, 


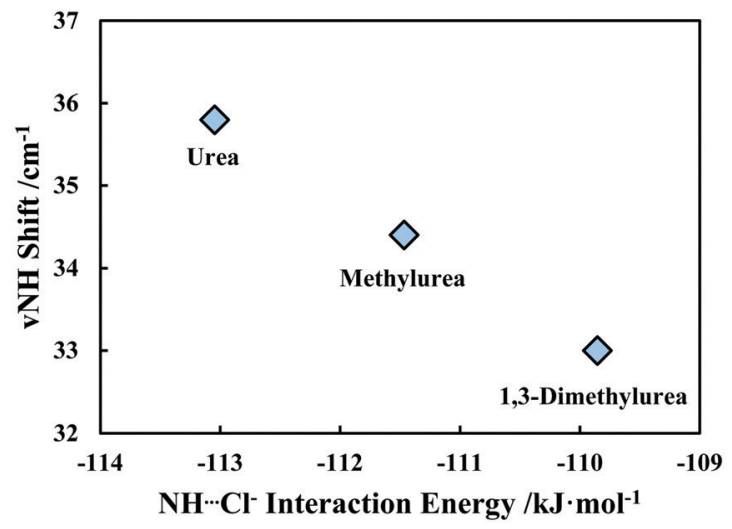

a)

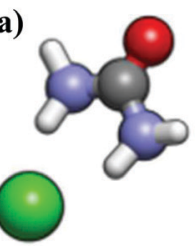

b)

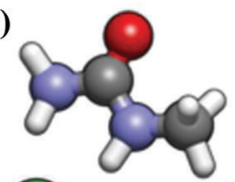

c)

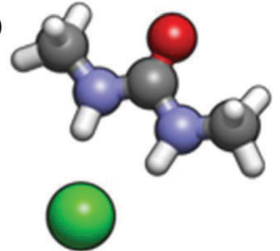

Fig. 7 Plot of $\mathrm{NH}$ frequency shift ( $\nu \mathrm{NH}$ (pure $\mathrm{HBD}$ ) - $\nu \mathrm{NH}$ (eutectic mixture)) versus electronic energy of interaction of HBD ...chloride pairs for eutectic mixtures based on cholinium chloride and urea, methylurea and 1,3-dimethylurea. The optimized geometries used to calculate the interaction energy are also depicted: (a) urea...chloride, (b) methylurea...chloride and (c) 1,3-dimethylurea...chloride.
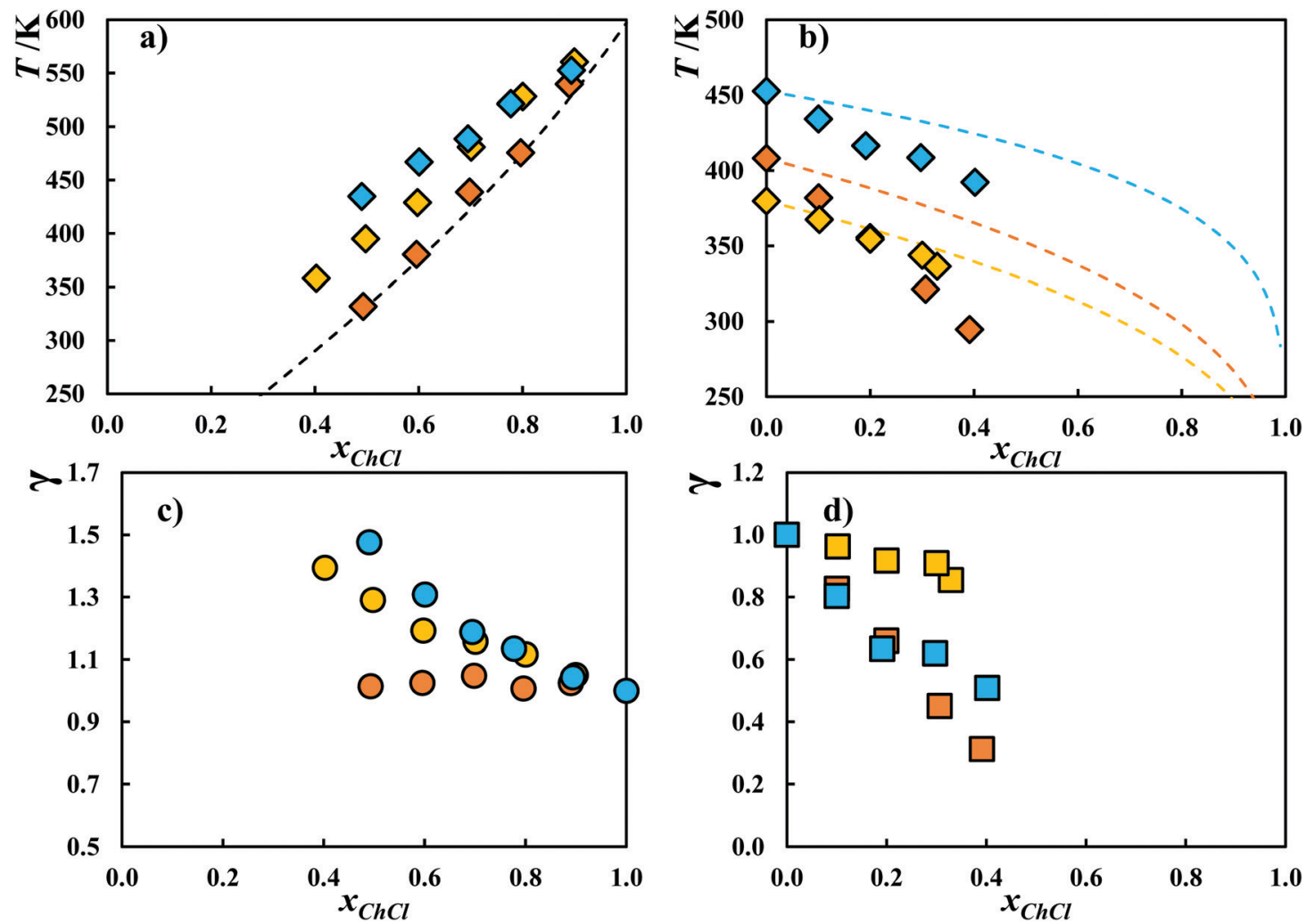

Fig. 8 Experimental melting curve $(\diamond)$ of $(a)$ cholinium chloride and (b) the urea-family component in the binary systems composed of cholinium chloride and urea (orange), 1,1-dimethylurea (blue) or 1,3-dimethylurea (yellow). The dashed lines represent the ideal melting curve of each component. The corresponding activity coefficients ( $\bigcirc$ for cholinium chloride and $\square$ for the urea-family component) are also included.

which are larger than those presented by 1,3-dimethylurea. This was not initially expected, since the increase of the cholinium chloride activity coefficient was expected to correlate with an increase of the 1,1-dimethylurea activity coefficient, 
following the trend observed for the previous systems studied in this section.

The computed atomic charges for urea, methylurea, 1,3dimethylurea, and 1,1-dimethylurea previously depicted in Fig. 4 allow for the understanding of electrostatic differences induced in urea by different methylation patterns. The addition of methyl groups results only in local effects on the molecular electrostatic field. The charges on nitrogen show the largest oscillations, from -0.64 from unfunctionalized urea, to around -0.50 for one methyl group to -0.37 for two methyl groups. The remaining charges show little variation. The oxygen charges remain mostly unchanged with a value near -0.45 and the central carbon atom and the four HBD protons show similar positive charges from +0.34 to +0.36 . This indicates that the carbonyl group should not play a determinant role in the changes observed by methylation, as already suggested by the thiourea results. In addition, the electrostatic part of the hydrogen bonding should be quite similar for all protons.

In order to further understand the variation of $\mathrm{N}-\mathrm{H} \cdots \mathrm{Cl}^{-}$ contacts a Non-Covalent Interaction (NCI) analysis was performed, which, based on subtle differences of the electronic density, graphically reveals the different intermolecular interactions. ${ }^{58,59}$ These results are reported in Fig. 9.

In the NCI analysis, larger binding interactions are found as larger green (dispersive) and blue (HB) NCI volumes. First, the fact that thiourea and urea show very similar NCI with the chlorine anion confirms, once more, that a very similar $\mathrm{N}-\mathrm{H} \cdots \mathrm{Cl}^{-}$interaction is the reason why the activity coefficients for both molecules, when mixed with $\mathrm{ChCl}$, are similar. The other volumes show only subtle differences, with the exception of 1,1-dimethylurea, which, since it has only one HBD proton available, shows a clearly reduced NCI volume and consequently should have the largest energy penalty. This was confirmed by the interaction energies, which were found to show a similar trend to the depressions of the melting point. Namely, excluding thiourea, the most stable pair was urea, followed by methylurea,

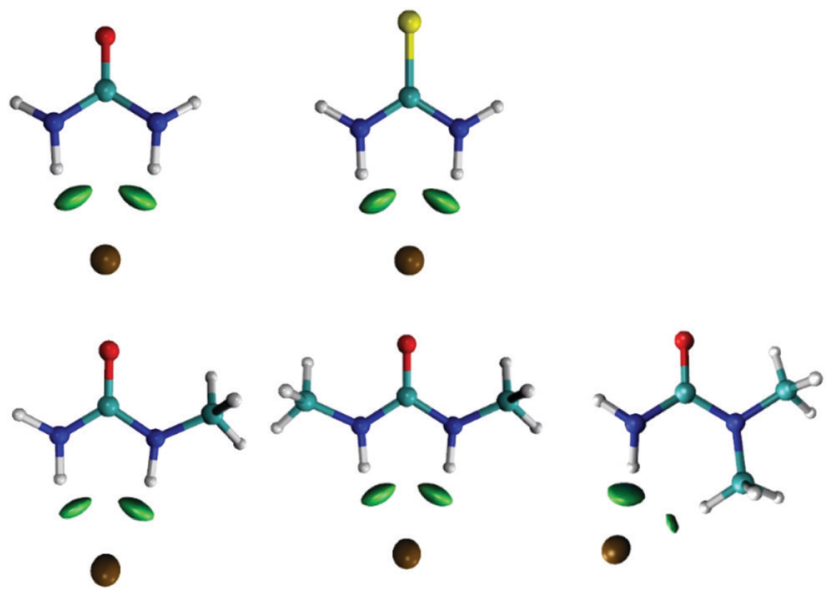

Fig. 9 Contact $\mathrm{N}-\mathrm{H} \cdots \mathrm{Cl}^{-}$interaction $\mathrm{NCl}$ analysis at the M06-2X-GIL-6$31+g(d, p) / M 06-2 X-6-31+g(d, p)$ level of theory for, from left to right, urea and thiourea (top) and, from left to right, methylurea, 1,3-dimethylurea and 1,1-dimethylurea (bottom).
Table 2 Melting and sublimation enthalpies for some of the urea-family compounds studied in this work, along with the resulting vaporization enthalpy, calculated from the difference between them

\begin{tabular}{llll}
\hline Compound & $\Delta_{\mathrm{m}} h / \mathrm{kJ} \mathrm{mol}^{-1}$ & $\Delta_{\mathrm{s}} h / \mathrm{kJ} \mathrm{mol}^{-1}$ & $\Delta_{\mathrm{v}} h / \mathrm{kJ} \mathrm{mol}^{-1}$ \\
\hline Urea & $14.6^{40}$ & $94.6^{60}$ & 80.0 \\
Methylurea & $12.5^{41}$ & $96.9^{60}$ & 84.4 \\
1,1-Dimethylurea & $29.11^{42}$ & $94.7^{60}$ & 65.6 \\
$1,3-$ Dimethylurea & $13.62^{43}$ & $87.6^{60}$ & 74.0
\end{tabular}

with a slightly superior interaction energy, 1,3-dimethylurea $\left(+5 \mathrm{~kJ} \mathrm{~mol}^{-1}\right)$ and 1,1-dimethylurea $\left(+16 \mathrm{~kJ} \mathrm{~mol}^{-1}\right)$. This extended correlation further supports the importance of the $\mathrm{N}-\mathrm{H} \cdot \mathrm{Cl}^{-}$interactions in the melting point depressions.

Another clarification to the unexpected behaviour of 1,1dimethylurea can be found looking at its pure component interactions. As mentioned above, the preferred type of interaction of urea in its pure crystalline state takes place between the oxygen of the carbonyl group and the two "trans"-protons, one from each amine group, in what is known as a head-to-tail interaction. ${ }^{57}$ In the liquid phase, the head-to-tail motif is likely to remain predominant, as evidenced in the Raman spectrum shown in Fig. 7a, where $\mathrm{N}-\mathrm{H}$ stretching modes stemming from head-to-tail contacts (3300-3400 $\mathrm{cm}^{-1}$ ) appear significantly more intense than those arising from the alternative centrosymmetric dimer arrangement $\left(3150-3250 \mathrm{~cm}^{-1}\right) .{ }^{38}$ By fully blocking one of the amine groups as in 1,1-dimethylurea this interaction is no longer possible, making this compound more prone to interact with the chloride anion, leading to unexpected large negative deviations from ideality. This interpretation can be corroborated and quantified using the vaporisation enthalpy of the urea-family, which, considering there is no association in the vapour phase, is an indicator of how strong the pure component interactions are in the liquid state. This value can be estimated by subtracting the melting enthalpy of the compound from its sublimation enthalpy. The results reported in Table 2 clearly show that the hypothetical liquid state of 1,1-dimethylurea is less energetically favourable when compared with the other ureas.

\section{Conclusions}

In this work, the solid-liquid equilibrium phase diagrams of cholinium chloride mixtures with urea and four modified ureas were experimentally measured. The second component of these systems was carefully chosen to represent a small modification in the structure of urea, corresponding to the selective blockage of its interaction centres. The results obtained were correlated against density functional theory-based computer models, which allowed us to conclude that the main interactions between urea and cholinium chloride are the hydrogen bonding between the chloride anion and two protons of urea, one from each amine group.

This work sheds light on the nature of the negative deviations from ideality presented by urea in cholinium chloride/urea mixtures, experimentally confirming the results of neutron diffraction by some authors ${ }^{31,32}$ regarding the dominant interactions in this system. It is still not clear, however, how the 
second component can be tailored to induce negative deviations from ideality in cholinium chloride. This would be very useful since it would enhance the melting temperature depression effect and is under investigation in our group.

\section{Conflicts of interest}

There are no conflicts to declare.

\section{Acknowledgements}

This work was developed in the scope of the project CICECO Aveiro Institute of Materials, POCI-01-0145-FEDER-007679 (Ref. FCT UID/CTM/50011/2019) and Associate Laboratory LSRELCM, POCI-01-0145-FEDER-006984 (Ref. FCT UID/EQU/50020/ 2019), and project MultiBiorefinery (POCI-01-0145-FEDER016403), all financed by national funds through the FCT/ MCTES (PIDDAC) and when appropriate co-financed by FEDER under the PT2020 Partnership Agreement. M. A. R. M. acknowledges financial support from NORTE-01-0145-FEDER-000006 funded by NORTE2020 through PT2020 and ERDF. L. P. S. acknowledges FCT for her PhD grant (SFRH/BD/135976/2018). C. F. A. acknowledges FCT for her PhD grant (SFRH/BD/129040/ 2017). M. M. N. and M. M. F. acknowledge FCT for their researcher contracts (IF/01468/2015 and IF/00894/2015 respectively) under the program IF 2015.

\section{References}

1 A. Shishov, A. Bulatov, M. Locatelli, S. Carradori and V. Andruch, Application of deep eutectic solvents in analytical chemistry. A review, Microchem. J., 2017, 135, 33-38.

2 A. Paiva, R. Craveiro, I. Aroso, M. Martins, R. L. Reis and A. R. C. Duarte, Natural Deep Eutectic Solvents - Solvents for the 21st Century, ACS Sustainable Chem. Eng., 2014, 2, 1063-1071.

3 Y. Dai, J. van Spronsen, G.-J. Witkamp, R. Verpoorte and Y. H. Choi, Natural deep eutectic solvents as new potential media for green technology, Anal. Chim. Acta, 2013, 766, 61-68.

4 E. L. Smith, A. P. Abbott and K. S. Ryder, Deep Eutectic Solvents (DESs) and Their Applications, Chem. Rev., 2014, 114, 11060-11082.

5 Q. Zhang, K. De Oliveira Vigier, S. Royer and F. Jérôme, Deep eutectic solvents: syntheses, properties and applications, Chem. Soc. Rev., 2012, 41, 7108-7146.

6 M. A. R. Martins, S. P. Pinho and J. A. P. Coutinho, Insights into the Nature of Eutectic and Deep Eutectic Mixtures, J. Solution Chem., 2018, DOI: 10.1007/s10953-018-0793-1.

7 D. O. Abranches, L. P. Silva, M. A. R. Martins, L. Fernandez, S. P. Pinho and J. A. P. Coutinho, Can cholinium chloride form eutectic solvents with organic chloride-based salts?, Fluid Phase Equilib., 2019, 493, 120-126.

8 A. P. Abbott, G. Capper, D. L. Davies, K. J. McKenzie and S. U. Obi, Solubility of Metal Oxides in Deep Eutectic
Solvents Based on Choline Chloride, J. Chem. Eng. Data, 2006, 51, 1280-1282.

9 A. P. Abbott, D. Boothby, G. Capper, D. L. Davies and R. K. Rasheed, Deep Eutectic Solvents Formed between Choline Chloride and Carboxylic Acids: Versatile Alternatives to Ionic Liquids, J. Am. Chem. Soc., 2004, 126, 9142-9147.

10 L. Fernandez, L. P. Silva, M. A. R. Martins, O. Ferreira, J. Ortega, S. P. Pinho and J. A. P. Coutinho, Indirect assessment of the fusion properties of choline chloride from solid-liquid equilibria data, Fluid Phase Equilib., 2017, 448, 9-14.

11 E. A. Crespo, L. P. Silva, M. A. R. Martins, L. Fernandez, J. Ortega, O. Ferreira, G. Sadowski, C. Held, S. P. Pinho and J. A. P. Coutinho, Characterization and Modeling of the Liquid Phase of Deep Eutectic Solvents Based on Fatty Acids/Alcohols and Choline Chloride, Ind. Eng. Chem. Res., 2017, 56, 12192-12202.

12 I. P. E. Macário, F. Jesus, J. L. Pereira, S. P. M. Ventura, A. M. M. Gonçalves, J. A. P. Coutinho and F. J. M. Gonçalves, Unraveling the ecotoxicity of deep eutectic solvents using the mixture toxicity theory, Chemosphere, 2018, 212, 890-897.

13 K. Radošević, M. Cvjetko Bubalo, V. Gaurina Srček, D. Grgas, T. Landeka Dragičević and I. Radojčić Redovniković, Evaluation of toxicity and biodegradability of choline chloride based deep eutectic solvents, Ecotoxicol. Environ. Saf., 2015, 112, 46-53.

14 A. P. Abbott, G. Capper, D. L. Davies, R. K. Rasheed and V. Tambyrajah, Novel solvent properties of choline chloride/ urea mixtures, Chem. Commun., 2003, 70-71.

15 A. van den Bruinhorst, L. J. B. M. Kollau, M. C. Kroon, J. Meuldijk, R. Tuinier and A. C. C. Esteves, A centrifuge method to determine the solid-liquid phase behavior of eutectic mixtures, J. Chem. Phys., 2018, 149, 224505.

16 X. Meng, K. Ballerat-Busserolles, P. Husson and J.-M. Andanson, Impact of water on the melting temperature of urea + choline chloride deep eutectic solvent, New J. Chem., 2016, 40, 4492-4499.

17 H. G. Morrison, C. C. Sun and S. Neervannan, Characterization of thermal behavior of deep eutectic solvents and their potential as drug solubilization vehicles, Int. J. Pharm., 2009, 378, 136-139.

18 S. Zhu, H. Li, W. Zhu, W. Jiang, C. Wang, P. Wu, Q. Zhang and $\mathrm{H}$. Li, Vibrational analysis and formation mechanism of typical deep eutectic solvents: An experimental and theoretical study, J. Mol. Graphics Modell., 2016, 68, 158-175.

19 S. Zahn, Deep eutectic solvents: similia similibus solvuntur?, Phys. Chem. Chem. Phys., 2017, 19, 4041-4047.

20 S. Zahn, B. Kirchner and D. Mollenhauer, Charge Spreading in Deep Eutectic Solvents, ChemPhysChem, 2016, 17, 3354-3358.

21 C. Yuan, K. Chu, H. Li, L. Su, K. Yang, Y. Wang and X. Li, In situ Raman and synchrotron X-ray diffraction study on crystallization of Choline chloride/Urea deep eutectic solvent under high pressure, Chem. Phys. Lett., 2016, 661, 240-245.

22 D. V. Wagle, L. Adhikari and G. A. Baker, Computational perspectives on structure, dynamics, gas sorption, and biointeractions in deep eutectic solvents, Fluid Phase Equilib., 2017, 448, 50-58. 
23 D. V. Wagle, C. A. Deakyne and G. A. Baker, Quantum Chemical Insight into the Interactions and Thermodynamics Present in Choline Chloride Based Deep Eutectic Solvents, J. Phys. Chem. B, 2016, 120, 6739-6746.

24 H. Sun, Y. Li, X. Wu and G. Li, Theoretical study on the structures and properties of mixtures of urea and choline chloride, J. Mol. Model., 2013, 19, 2433-2441.

25 R. Stefanovic, M. Ludwig, G. B. Webber, R. Atkin and A. J. Page, Nanostructure, hydrogen bonding and rheology in choline chloride deep eutectic solvents as a function of the hydrogen bond donor, Phys. Chem. Chem. Phys., 2017, 19, 3297-3306.

26 S. L. Perkins, P. Painter and C. M. Colina, Molecular Dynamic Simulations and Vibrational Analysis of an Ionic Liquid Analogue, J. Phys. Chem. B, 2013, 117, 10250-10260.

27 A. Pandey, Bhawna, D. Dhingra and S. Pandey, Hydrogen Bond Donor/Acceptor Cosolvent-Modified Choline ChlorideBased Deep Eutectic Solvents, J. Phys. Chem. B, 2017, 121, 4202-4212.

28 A. Pandey and S. Pandey, Solvatochromic Probe Behavior within Choline Chloride-Based Deep Eutectic Solvents: Effect of Temperature and Water, J. Phys. Chem. B, 2014, 118, 14652-14661.

29 V. Migliorati, F. Sessa and P. D'Angelo, Deep eutectic solvents: A structural point of view on the role of the cation, Chem. Phys. Lett. X, 2019, 2, 100001.

30 S. Kaur, S. Sharma and H. K. Kashyap, Bulk and interfacial structures of reline deep eutectic solvent: a molecular dynamics study, J. Chem. Phys., 2017, 147, 194507.

31 O. S. Hammond, D. T. Bowron and K. J. Edler, Liquid structure of the choline chloride-urea deep eutectic solvent (reline) from neutron diffraction and atomistic modelling, Green Chem., 2016, 18, 2736-2744.

32 M. Gilmore, L. M. Moura, A. H. Turner, M. Swadźba-Kwaśny, S. K. Callear, J. A. McCune, O. A. Scherman and J. D. Holbrey, A comparison of choline:urea and choline:oxalic acid deep eutectic solvents at 338 K, J. Chem. Phys., 2018, 148, 193823.

33 E. O. Fetisov, D. B. Harwood, I.-F. W. Kuo, S. E. E. Warrag, M. C. Kroon, C. J. Peters and J. I. Siepmann, First-Principles Molecular Dynamics Study of a Deep Eutectic Solvent: Choline Chloride/Urea and Its Mixture with Water, J. Phys. Chem. B, 2018, 122, 1245-1254.

34 B. Doherty and O. Acevedo, OPLS Force Field for Choline Chloride-Based Deep Eutectic Solvents, J. Phys. Chem. B, 2018, 122, 9982-9993.

35 C. D'Agostino, R. C. Harris, A. P. Abbott, L. F. Gladden and M. D. Mantle, Molecular motion and ion diffusion in choline chloride based deep eutectic solvents studied by $1 \mathrm{H}$ pulsed field gradient NMR spectroscopy, Phys. Chem. Chem. Phys., 2011, 13, 21383.

36 Y. Cui, K. D. Fulfer, J. Ma, T. K. Weldeghiorghis and D. G. Kuroda, Solvation dynamics of an ionic probe in choline chloride-based deep eutectic solvents, Phys. Chem. Chem. Phys., 2016, 18, 31471-31479.

37 C. R. Ashworth, R. P. Matthews, T. Welton and P. A. Hunt, Doubly ionic hydrogen bond interactions within the choline chloride-urea deep eutectic solvent, Phys. Chem. Chem. Phys., 2016, 18, 18145-18160.

38 C. F. Araujo, J. A. P. Coutinho, M. M. Nolasco, S. F. Parker, P. J. A. Ribeiro-Claro, S. Rudić, B. I. G. Soares and P. D. Vaz, Inelastic neutron scattering study of reline: shedding light on the hydrogen bonding network of deep eutectic solvents, Phys. Chem. Chem. Phys., 2017, 19, 17998-18009.

39 D. Carriazo, M. C. Serrano, M. C. Gutiérrez, M. L. Ferrer and F. del Monte, Deep-eutectic solvents playing multiple roles in the synthesis of polymers and related materials, Chem. Soc. Rev., 2012, 41, 4996-5014.

40 U. S. Rai and R. N. Rai, Some Physicochemical Studies on Organic Eutectics and Molecular Complex: Urea - $p$-nitrophenol System, J. Mater. Res., 1999, 14, 1299-1305.

41 P. Ferloni and G. Della Gatta, Heat capacities of urea, $N$-methylurea, $N$-ethylurea, $N-(n)$ propylurea, and $N$-(n)butylurea in the range 200 to $360 \mathrm{~K}$, Thermochim. Acta, 1995, 266, 203-212.

42 W. E. Acree, Thermodynamic properties of organic compounds: enthalpy of fusion and melting point temperature compilation, Thermochim. Acta, 1991, 189, 37-56.

43 G. Della Gatta and D. Ferrq, Enthalpies of fusion and solidto-solid transition, entropies of fusion for urea and twelve alkylureas, Thermochim. Acta, 1987, 122, 143-152.

44 K.-J. Kim, C.-H. Lee and S.-K. Ryu, Solubility of Thiourea in C1 to C6 1-Alcohols, J. Chem. Eng. Data, 1994, 39, 228-230.

45 L. Gontrani, N. V. Plechkova and M. Bonomo, In-Depth Physico-Chemical and Structural Investigation of a Dicarboxylic Acid/Choline Chloride Natural Deep Eutectic Solvent (NADES): A Spotlight on the Importance of a Rigorous Preparation Procedure, ACS Sustainable Chem. Eng., 2019, 7(14), 12536-12543.

46 K. M. Harmon and G. F. Avci, Hydrogen bonding, J. Mol. Struct., 1986, 140, 261-268.

47 R. L. Collin, Polymorphism And Radiation Decomposition Of Choline Chloride 1, J. Am. Chem. Soc., 1957, 79, 6086.

48 V. S. Bernales, A. V. Marenich, R. Contreras, C. J. Cramer and D. G. Truhlar, Quantum Mechanical Continuum Solvation Models for Ionic Liquids, J. Phys. Chem. B, 2012, 116, 9122-9129.

49 C. Bannwarth, S. Ehlert and S. Grimme, GFN2-xTB-An Accurate and Broadly Parametrized Self-Consistent TightBinding Quantum Chemical Method with Multipole Electrostatics and Density-Dependent Dispersion Contributions, J. Chem. Theory Comput., 2019, 15, 1652-1671.

50 M. J. Frisch, G. W. Trucks, H. B. Schlegel, G. E. Scuseria, M. A. Robb, J. R. Cheeseman, G. Scalmani, V. Barone, G. A. Petersson, H. Nakatsuji, X. Li, M. Caricato, A. Marenich, J. Bloino, B. G. Janesko, R. Gomperts, B. Mennucci, H. P. Hratchian, J. V. Ortiz, A. F. Izmaylov, J. L. Sonnenberg, D. Williams-Young, F. Ding, F. Lipparini, F. Egidi, J. Goings, B. Peng, A. Petrone, T. Henderson, D. Ranasinghe, V. G. Zakrzewski, J. Gao, N. Rega, G. Zheng, W. Liang, M. Hada, M. Ehara, K. Toyota, R. Fukuda, J. Hasegawa, M. Ishida, T. Nakajima, Y. Honda, O. Kitao, H. Nakai, T. Vreven, K. Throssell, J. A. Montgomery, Jr., J. E. Peralta, F. Ogliaro, M. Bearpark, J. J. Heyd, E. Brothers, K. N. Kudin, V. N. Staroverov, T. Keith, R. Kobayashi, J. Normand, K. Raghavachari, A. Rendell, J. C. Burant, S. S. Iyengar, J. Tomasi, M. Cossi, 
J. M. Millam, M. Klene, C. Adamo, R. Cammi, J. W. Ochterski, R. L. Martin, K. Morokuma, O. Farkas, J. B. Foresman and D. J. Fox, Gaussian 09, Revision A.02, Gaussian, Inc., Wallingford CT, 2016.

51 TURBOMOLE V7.1 2016, a development of University of Karlsruhe and Forschungszentrum Karlsruhe $\mathrm{GmbH}$, 1989-2007, TURBOMOLE GmbH, since 2007; available from http://www.turbomole.com.

52 J. M. Prausnitz, R. N. Lichtenthaler and E. G. de Azevedo, Molecular Thermodynamics of Fluid-Phase Equilibria, Prentice Hall, 1998.

53 J. A. P. Coutinho, S. I. Andersen and E. H. Stenby, Evaluation of activity coefficient models in prediction of alkane solidliquid equilibria, Fluid Phase Equilib., 1995, 103, 23-39.

54 R. Keuleers, H. O. Desseyn, B. Rousseau and C. Van Alsenoy, Vibrational Analysis of Urea, J. Phys. Chem. A, 1999, 103, 4621-4630.

55 Y. Saito, K. Machida and T. Uno, Vibrational spectra of methylurea, Spectrochim. Acta, Part A, 1975, 31, 1237-1244.

56 R. Keuleers, H. O. Desseyn, B. Rousseau and C. Van Alsenoy, Solids Modeled by ab Initio Crystal Field Methods. 21. Study of the Structure and Vibrational Spectrum of $N, N^{\prime}$ Dimethylurea in the Gas Phase and in Its Cc Crystal Phase, J. Phys. Chem. A, 2000, 104, 5946-5954.

57 A. Shukla, E. D. Isaacs, D. R. Hamann and P. M. Platzman, Hydrogen bonding in urea, Phys. Rev. B: Condens. Matter Mater. Phys., 2001, 64, 52101.

58 C. Lefebvre, H. Khartabil, J.-C. Boisson, J. Contreras-García, J.-P. Piquemal and E. Hénon, The Independent Gradient Model: A New Approach for Probing Strong and Weak Interactions in Molecules from Wave Function Calculations, ChemPhysChem, 2018, 19, 724-735.

59 C. Lefebvre, G. Rubez, H. Khartabil, J.-C. Boisson, J. Contreras-García and E. Hénon, Accurately extracting the signature of intermolecular interactions present in the NCI plot of the reduced density gradient versus electron density, Phys. Chem. Chem. Phys., 2017, 19, 17928-17936.

60 D. Zaitsau, G. Kabo, A. Kozyro and V. Sevruk, The effect of the failure of isotropy of a gas in an effusion cell on the vapor pressure and enthalpy of sublimation for alkyl derivatives of carbamide, Thermochim. Acta, 2003, 406, 17-28. 